Muszkieta Radosław, Oleśniewicz Piotr, Cieślicka Mirosława, Napierała Marek. Monitoring and assessment activities and indications of empathic behavior of the examined teachers during physical education lessons. Pedagogy and Psychology of Sport. 2015;1(1):4-10. eISSN 2450-6605. DOI http://dx.doi.org/10.5281/zenodo.44537 http://apcz.umk.pl/czasopisma/index.php/PPS/article/view/12215

Pedagogy and Psychology of Sport, Vol. 1 / No 1, 2015

Muszkieta, Oleśniewicz, Cieślicka, Napierała p. 4-10

\title{
Monitoring and assessment activities and indications of empathic behavior of the examined teachers during physical education lessons
}

\author{
Radosław Muszkieta *, Piotr Oleśniewicz **, Mirosława Cieślicka ***, Marek Napierała $* * *$ \\ * Academy of Sports and Science, Poland ** University School of Physical Education, Wroclaw, \\ Poland $* * *$ Kazimierz Wielki University, Bydgoszcz, Poland
}

DOI 10.5281/zenodo.44537

Keywords: physical education lessons, teachers, empathic behavior, evaluation Abstract

The material of the studies was the physical education teachers of randomly chosen Poznan (Poland) schools: primary, grammar, and secondary schools. The studies involved 584 physical education teachers. The studies were conducted in the school year of 19992000. For the studies, an observation method was applied consisting in lesson observations during physical education lessons carried out by physical education teachers. The results of the studies form characteristic upward or downward tendencies. The higher the educational stage the higher the percentage value for the teachers who: a) assess attitudes and behavior of the students; b) monitor and assess knowledge of the students in the field of physical culture; c) assess with grades or points motor and organizational skills; d) assess verbally tasks' achievement; e) apply and introduce self-monitoring and self-assessment of knowledge, skills, attitudes, and physical fitness of the students. The downward tendencies were observed exclusively for monitoring attitudes and behavior of the students (i.e. having sports outfit, activity, involvement, attendance, etc.). The examined women were characterized by better and more positive empathic behavior. For all parameters, the women appeared to be better.

\section{Introduction}

In order to increase the knowledge about the condition of monitoring and assessment activities carried out by the physical education teachers, an attempt was made to observe the lessons. It seems that such verification of school practice is to considerably facilitate and improve the discussed issue. For the observation of various physical education lessons at three educational stages, an additional factor has been considered - empathic behavior of the examined teachers, which significantly, or even principally, influences didactic-educational effects, particularly in case of carrying out monitoring and assessment activities (Muszkieta 2004, 2005).

\section{Material and methods}

The material of the studies was the physical education teachers of randomly chosen Poznan (Poland) schools: 40 primary schools, 30 grammar schools, and 20 secondary schools. The studies involved 584 physical education teachers, including 331 women and 253 men. All the examined teachers had higher master's education with the major in

physical education. The studies were conducted in the school year of 1999-2000 (from September 1999 to May 2000).

For the studies, an observation method was applied consisting in lesson observations during physical education lessons carried out by physical education teachers. In the primary schools, 256 lessons of physical education were observed: gymnastics $(\mathrm{N}=60)$, athletics $(\mathrm{N}=18)$, volleyball $(\mathrm{N}=40)$, handball $(\mathrm{N}=28)$, football $(\mathrm{N}=22)$, basketball $(\mathrm{N}=30)$, swimming $(\mathrm{N}=8)$, sports games $(\mathrm{N}=50)$. In the grammar schools, 173 lessons were observed: gymnastics $(\mathrm{N}=24)$, athletics 
$(\mathrm{N}=15)$, volleyball (38), handball $(\mathrm{N}=22)$, football $(\mathrm{N}=22)$, basketball $(\mathrm{N}=34)$, music and motor forms $(\mathrm{N}=18)$. In secondary school, 155 lessons were observed: gymnastics $(\mathrm{N}=30)$, athletics $(\mathrm{N}=17)$, volleyball $(\mathrm{N}=24)$, handball $(\mathrm{N}=21)$, football $(\mathrm{N}=20)$, basketball $(\mathrm{N}=24)$, music and motor forms $(\mathrm{N}=19)$.

Observing the physical education lessons, the course of the activity was registered in the prepared protocols, considering the lesson division into 4 parts: part I- initial, part Ha - warm-up (shaping exercises), part lib - core, part III - final.

\section{Analysis of research results}

In the analysis of monitoring and assessment activities of physical education students, the following components were distinguished: monitoring of personal hygiene (outfit, body, etc.), monitoring and assessment of attitudes and behavior of the students (i.e. having sports outfit, activity, involvement, attendance), monitoring and assessment of students' knowledge, assessment in grades or points concerning the particular skills (motor, utilitarian, organizational), assessment in grades or points concerning physical fitness, verbal assessment of carrying out the tasks (i.e. praise, reprimand), self-assessment and self-monitoring of the students (knowledge, skills, fitness, attitudes and behavior). In the protocol, lack of monitoring and assessment of a student during particular stages of a lesson was taken down.

The other area of analysis following the observations was the identification of empathic behavior indications of the examined physical education teachers during particular lessons. The indications of empathic behavior of the teachers were the following: sincere smile of a teacher, an ability to comfort the students in difficult situations, sympathy of a teacher in case of student's failure, happiness about student's performance, accurate friendly referring to a student, personal culture of a teacher, and proper behavior in different didactic-educational situations. Furthermore, there was reprehensible behavior of particular teachers observed during the lessons (i.e. shout, fisticuffs attempts, offensive referring to the students, etc.) and total lack of empathic behavior indications of the examined teachers.

Basing on the analysis of the results, it was found that more than $8 \%$ of the studied physical education teachers of primary school did not introduce any form of monitoring and assessment of a student during the lessons. For all types of lessons, these were mostly the men - at average $11 \%$, thus, $6.4 \%$ of the women did not show any monitoring and assessment activity during the lessons. Generally, the students were assessed verbally (total - 67.2\%; the women $67.9 \%$; the men - 66\%). It particularly concerned part IIA and IIB, less frequently part III and hardly ever part I of a lesson. More than $90 \%$ of the studied women and men monitor personal hygiene of the students during the initial part of a lesson. There is no such element in the following parts of a lesson. Also, the teachers highly monitor the attitudes and behavior of the students. It is important that the percentage values of this component decrease as the particular parts of a lesson carry on, increase at the end of a lesson, i.e. at the closing stages. The following aspects are assessed with a grade: attitudes and behavior of the students (total - 25\%; the women - 24.4\%; the men - 26\%), and motor and organizational skills of the students (total - 20.3\%; the women - 18.6\%; the men - 23\%). Notwithstanding the common opinions, the teachers rather infrequently give the numerical or point grades for the performance in physical fitness, motor predispositions and skills. It concerns no more than $5.1 \%$ of the observed lessons, including $7 \%$ of the lessons carried out by the men and $3.8 \%$ by the women. Unfortunately, merely $10 \%$ of the studied teachers monitor and assess the students' knowledge of physical education. Lack of monitoring the knowledge and, consequently, poor knowledge transferred to the students considerably influence the low level of children's prosomatic and prohealth attitudes and behavior.

The primary school stage is a phase of cognitive, emotional, and psychophysical activity of children. According to the contemporary pedagogical tendencies, the activity should be 
developed through considerable development of independence and creativity of children. One of the most important elements of independence and creativity of children is self-monitoring and selfassessment of their performance. Unfortunately, according to the studies, self-monitoring is applied by no more than $9.4 \%$ of the teachers ( $9 \%$ of the women, $10 \%$ of the men), and self-assessment by $7 \%$ of the primary school teachers (9\% of the women, $8 \%$ of the men). To the highest degree, though still not satisfactory, the selfassessment and self-monitoring were applied at the lessons of: athletics, handball, football, and swimming.

The disparities between the men and women in particular components of monitoring and assessment of students' performance are not statistically important.

In the previous chapters, the state of preconditions of monitoring and assessment activity of physical education teachers was discussed, including empathy. At that point, an attempt was made to determine the indications of empathic behavior of the teachers during "live" lessons of physical education carried out on three educational levels.

The teachers of primary schools show extensive empathic behavior. Most frequently these are: appropriate friendly referring to the students (total: $70.7 \%$; the women $-72.4 \%$; the men $68 \%$ ) and sincere smile of a teacher (total: $58.6 \%$; the women $-62.2 \%$; the men - 53\%). No more than every second physical education teacher of primary school represents appropriate level of personal culture, which is very pessimistic information. Provided that the understanding of the "physical culture" idea varies, the result is by all means unsatisfactory.

The two features most strictly connected with empathy, i.e. an ability to comfort the students in difficult situations and sympathy of a teacher in case of students' failures are characterized by a very low rank. Every fourth teacher was found to take advantage of the features during physical education lessons. To a greater extent satisfactory in this educational activity appeared to be the women. More than $30 \%$ of the studied teachers $(33.3 \%$ of the women, $31 \%$ of the men) expressed happiness for students' performance. This particular component was generally found for the parts IIA and IIB of a lesson, specifically closing stages and final discussion of a lesson. In this case, the percentage value of the men was predominant for all types of lessons, except for swimming, sports games, and football.

Primary school is a place provoking stress and discomfort of a child. Nearly $12 \%$ of the examined teachers were characterized by reprehensible behavior (10.9\% of the women, $13 \%$ of the men), i.e. by shouting, fisticuffs attempts, fisticuffs, offensive referring to the students, disregarding the students, mocking at the students - particularly referring to their failures. It may be stated that such situation concerns every fourth teacher. The reasons for such behavior are varied and multilevel, though unacceptable in learning and educating children. According to the analysis, it was also stated that nearly $20 \%$ of the studied teachers (17.3\% of the women, $22 \%$ of the men) did not show any indications of empathic behavior during the lessons. Such attitude varied depending on the parts and types of the lessons.

Monitoring and assessment activities and indications of empathic behavior of the teachers of Poznań grammar schools were observed during the lessons of 7 types. For more than $9 \%$ of the teachers $(8.5 \%$ of the women, $10.1 \%$ of the men) no monitoring and assessment activities at particular stages of a lesson were found. The teachers monitored the following aspects: personal hygiene (96\% in part I of a lesson); attitudes and behavior of the students in the field of activity, involvement, attendance, sports outfit (total: 38.2\%; the women - 41.5\%, the men - 34.2\%); carrying out the tasks (total: 69.4\%; the women - 70.2\%; the men - 68.4\%). Verbal assessment of the accuracy of task accomplishment mostly concerns the following parts of a physical education lesson: IIA (total - approx. 93\%), IIB (total -approx. 92\%), and III (total - approx. 75\%).

In case of the teachers of primary schools, a decreased percentage of the teachers who apply the numerical or point grades was found. The assessment concerned: motor, utilitarian, and organizational skills (total $-29.5 \%$; the women $-30.9 \%$; the men $-27.8 \%$ ); attitudes and behavior 
(total: $28.3 \%$; the women $-27.7 \%$; the men $29.1 \%$ ), and the components of physical fitness (total: $14.5 \%$; the women - $13.8 \%$; the men - 15.2\%). The disparities between the female and male teachers are of no statistical importance.

An increase of applying self-assessment and self-monitoring of the students was found for the grammar school teachers in comparison with the primary school teachers. $26 \%$ of the examined grammar school teachers considered in their educational work the elements of self-monitoring of the students, including $28.7 \%$ of the women and $22.8 \%$ of the men. Comparable were the percentage values for the grammar school teachers who introduce self-assessment to educational process. Nearly $21 \%$ of the studied teachers developed independence and creativity of the students through the use of self-assessment of students' performance $(20.2 \%$ of the women, $21.5 \%$ of the men). The teachers of grammar schools appeared to best apply self-monitoring and self-assessment for the athletics and music-motor forms of a lesson. It should be emphasized at this point that the reformers of the Polish educational system defined the III stage of education, i.e. grammar school, to be a phase of the development of adolescents' independence. According to the presented data, the grammar school teachers meet the requirement more effectively than the teachers of primary schools, though it is not the satisfactory level yet. This indicator should reach the value of $100 \%$.

For the five indications of empathic behavior, increased percentage value was found in case of the grammar school teachers in comparison with the pedagogues of primary schools, and it concerns the following aspects: sincere smile of a teacher during a lesson (total - 71.1\%; the women - 75.5\%; the men - 65.8\%), happiness for the students' performance (total - 41\%; the women $-43.6 \%$; the men $-38 \%$ ), friendly referring to the students (total $-84.4 \%$; the women $87.2 \%$; the men - 81\%), personal culture (total - 72.3\%; the women - 78.7\%; the men - 64.6\%), and accurate behavior of a teacher in various didactic-educational situations of the lesson process (total $-30.1 \%$; the women $-33 \%$; the men $-26.6 \%$ ). For all of the above-mentioned components, the women were predominant, as in case of the primary schools.

The percentage values of two indicators of empathic behavior are similar to those of the primary school, i.e. an ability to comfort the students in difficult situations (total - 24.9\%; the women $-29.8 \%$; the men - 19\%), and sympathy of a teacher in case of student's failure (total $23.7 \%$; the women $-27.7 \%$; the men - 19\%). Yet again, the women were predominant in case of these two components.

Analyzing the results of the studies presented in Table 163, it was found that the reprehensible behavior of the teachers remains at the same level (total - 11\%; the women - 8.5\%; the men - 13.9\%), and similarly the lack of indications of empathic behavior (total - 17.3\%; the women $-16 \%$; the men - 19\%). Unfortunately, the men more frequently than the women do not show any empathic behavior or their behavior is reprehensible), which was particularly evident in case of the lessons on athletics, volleyball, and handball.

Monitoring and assessment activities and the indications of empathic behavior of the teachers of Poznań secondary schools were observed during the physical education lessons of 7 types, just as in case of the grammar schools. Analyzing the results of the studies presented in Table 164 concerning the examined teachers of secondary schools, first of all, it should be stated that the percentage value of the teachers applying selfmonitoring and self-assessment of students' performance in physical education increases. Nearly $30 \%$ of the examined teachers introduced selected forms of self-monitoring to the lesson process (30.9\% of the women, $27 \%$ of the men), and $33.6 \%$ of the teachers introduced and applied self-assessment for their students $(35.8 \%$ of the women, $31.1 \%$ of the men). Unfortunately, the condition is still unsatisfactory. At this particular stage of education, students' awareness, independence, responsibility, ability to make decisions, and creativity constitute basic competence which should be provided by a school, the teachers and tutors. Such competence might be acquired, among other things, through effective and systematic 
use of self-monitoring and self-assessment of students' performance. Therefore, a question occurs: does the Polish school fulfill the contemporary requirements of the reform of education system; does it teach and educate present-day members of a society?

The physical education teachers of secondary schools mostly monitor the following aspects in a lesson process: personal hygiene (outfit, body, etc.), particularly at the initial stage of a lesson ( $93 \%$ of the examined group); attitudes and behavior of the students, in this case emphasizing part I of a lesson rather than the parts IIA and IIB. It was found that the value of the indicator concerning knowledge monitoring and assessment considerably increased in comparison with the schools of lower educational stage. Therefore, it may be assumed that level of transfer of knowledge about physical culture is higher and more effective than in case of the primary and grammar schools. However, this level should neither satisfy the teachers themselves nor the pedagogical authorities. No more than $1 / 3$ of the high school teachers understand the importance of achieving the cognitive aims of physical culture.

At this educational stage, a teacher's verbal assessment of a student's performance was overestimated. Mote than $77 \%$ of the examined teachers applied verbal assessment of the students' performance $(77.8 \%$ of the women, $77.1 \%$ of the men). Considering the students' age, their intellectual, emotional, and psychophysical level, it should be assumed that it is a didactic mistake to provide the students, to such a great extent, with additional motivating and directing stimuli through the use of verbal assessment of their performance, correcting their mistakes, and providing with a praise or reprimand. This particular problem requires further scientific analysis supported by reliable and objective investigation instruments.

The examined teachers of secondary schools assessed the students applying grades or points in the following fields: attitudes and behavior (total $-36.1 \%$; the women - 37\%; the men $35.1 \%$ ), motor, utilitarian, and organizational skills (total $-35.5 \%$; the women $-37 \%$; the men $33.8 \%$ ), components of physical fitness (total $-13.6 \%$; the women $-11.1 \%$; the men $-16.2 \%$ ). The values of the indicators were very alike for particular types of lessons. Every tenth studied teacher did not apply any form of monitoring and assessment of the students' performance at particular stages of a lesson.

The percentage values concerning the indications of empathic behavior for the examined women - physical education teachers were higher than for the men representing Poznań secondary schools. Only the accurate friendly referring to a student remained at the same level (total - 79.4\%; the men - 79.7\%; the women - 79\%). A satisfactory state of empathic behavior was found concerning: sincere smiling at the students (total $-70.3 \%$, the women $-72.8 \%$, the men $-67.6 \%$ ), personal culture (total - 61.9\%; the women - 69.1\%; the men - 54.1\%), happiness for students' performance (total - 52.3\%; the women $-53.1 \%$; the men - 51.4\%). The other three important indicators of empathic behavior of the physical education teachers of secondary schools were characterized by a higher level than it was found for the teachers of primary and grammar schools, thus still unsatisfactory with reference to the social-educational needs and expectations. The indicators concern: the abilities to comfort the students in difficult situations (total - 29\%; the women - 37\%; the men - 20.3\%), sympathy of a teacher in case of students' failure (total - 29\%; the women $-35.7 \%$; the men $-21.6 \%$ ), and accurate behavior of a teacher in difficult didacticeducational situations (total - 28.4\%; the women - 35.8\%; the men-20.3\%).

On the basis of the analysis, it was found that $9.7 \%$ of the physical education teachers of secondary schools were characterized by reprehensible behavior $(9.9 \%$ of the women and $9.5 \%$ of the men). The negative behavior varied at particular stages of a lesson, however, it is evident that every tenth studied teacher is beyond the teacher-tutor model. Furthermore, the percentage value of the teachers characterized by the lack of any indications of empathic behavior remained at the same level, with reference to the teachers of primary and grammar schools. The problem concerned $17.4 \%$ of the secondary schools teachers, including $16.1 \%$ of the women and $18.9 \%$ of the men. 


\section{Summary}

The results of the studies form characteristic upward or downward tendencies. The higher the educational stage the higher the percentage value for the teachers who: a) assess attitudes and behavior of the students; b) monitor and assess knowledge of the students in the field of physical culture; c) assess with grades or points motor and organizational skills; d) assess verbally tasks' achievement; e) apply and introduce self-monitoring and selfassessment of knowledge, skills, attitudes, and physical fitness of the students. The downward tendencies were observed exclusively for monitoring attitudes and behavior of the students (i.e. having sports outfit, activity, involvement, attendance, etc.). Relatively similar level was found in case of the monitoring personal hygiene of the students and the lack of monitoring and assessment activities at particular stages of a lesson. No statistically significant disparities were found between the studied women and men.

The examined women were characterized by better and more positive empathic behavior. For all parameters, the women appeared to be better. Statistically important disparities, to the women's advantage, were found concerning the abilities to comfort the students in difficult situations and sympathy in case of failure. The least considerable indications of empathic behavior were observed for the teachers of primary schools, which is interesting with reference to the age of the children the teachers have contact with. Higher percentage values of empathic behavior characterized the grammar and secondary school teachers. The highest percentage values of grammar school teachers were observed for empathic behavior concerning: sincere smile at the children, friendly referring to the students, personal culture, and accurate behavior in various didactic-educational situations. The secondary school teachers were dominant in the following fields: abilities to comfort 
Pedagogy and Psychology of Sport, Vol. 1 / No 1, 2015

Muszkieta, Oleśniewicz, Cieślicka, Napierała p.4-10

the students in difficult situations, sympathy in case of failure, and happiness for students' performance. The examined men predominated over the women as far as reprehensible behavior is concerned and showed more considerable lack of indications of empathic behavior.

\section{Bibliography}

Muszkieta R. (2004). Ocenianie osiagnięć uczniów przez nauczycieli wychowania fizycznego. Poznań. Muszkieta R. (2005). Physical education teacher - evaluation of students' performance. Wydawnictwo WIGO, Poznań.

\section{Kontakt do autorów:}

prof. Radosław Muszkieta

prof. Piotr Oleśniewicz prof.

Marek Napierała dr

Mirosława Cieślicka

radek@muszkieta.com

piotr.olesniewicz@

awf.wroc.pl

nkeram@poczta.onet.pl

cudaki@op.pl 